\title{
Art Markets and Digital Histories
}

\author{
Sandra van Ginhoven $1, *$ (i) and Claartje Rasterhoff ${ }^{2, *(1)}$ \\ 1 Project for the Study of Collecting and Provenance, Getty Research Institute, Los Angeles, CA 90049, USA \\ 2 Department of History, University of Amsterdam, 1012 WX Amsterdam, The Netherlands \\ * Correspondence: svanginhoven@getty.edu (S.v.G.); c.rasterhoff@uva.nl (C.R.)
}

Received: 2 August 2019; Accepted: 6 August 2019; Published: 21 August 2019

check for updates

\begin{abstract}
This Special Issue of Arts investigates the use of digital methods in the study of art markets and their histories. Digital art history or historical research facilitated by computer-technology in general is omnipresent in academia and increasingly supported by an infrastructure of seminars, workshops, networks, journals and other platforms for sharing results, exchanging notes and developing criticism. As the wealth of historical and contemporary data is rapidly expanding and digital technologies are becoming integral to research in the humanities and social sciences, it is high time to reflect on the different strategies that art market scholars employ to navigate and negotiate digital techniques and resources.
\end{abstract}

Keywords: art markets; digital history; editorial

This Special Issue of Arts investigates the use of digital methods in the study of art markets and their histories. Digital art history or historical research facilitated by computer-technology in general is omnipresent in academia and increasingly supported by an infrastructure of seminars, workshops, networks, journals, and other platforms for sharing results, exchanging notes, and developing criticism. ${ }^{1}$ As the wealth of historical and contemporary data rapidly expands and digital technologies become integral to research in the humanities and social sciences, it is high time to reflect on the different strategies that art market scholars employ to navigate and negotiate digital techniques and resources.

The history of art markets is a particularly interesting subfield for observing the use and development of digital methods in historical and contemporary areas of study. The tradition of computational scholarship in this particular line of research dates back to well before the 1980s and is inextricably linked to the subdisciplines of 'economics of art' and 'cultural economics', as well as to 'economic art history' and 'social history of art' $^{2}$ Recurring overarching questions include the following: when and where did art markets emerge and how did they develop across time and space, what made them develop more rapidly or successfully in particular places and periods, how are artistic changes and innovations explained by changing market conditions and tastes, and how can the (commercial) success of specific artists, styles, themes, or artistic communities be explained? Besides these shared thematic questions and interests, the history of art markets is also characterized by a specific approach, as many researchers are trained in or borrow from social sciences research methods and then adapt them to the specifics of historical art markets. Art markets (and markets for cultural goods in general) are characterized by relatively high levels of demand and quality uncertainty, and as a result, both market participants and researchers grapple with elusive concepts such as taste, value, reputation, status, novelty that do not fit easily in economic and computational models.

1 Consider for instance the recently founded International Journal for Digital Art History; http://www.dah-journal.org/. Cf. Baca et al. $(2013,2019)$.

2 This range is also at the core of the recently founded The International Art Market Studies Association (TIAMSA); https://www.artmarketstudies.org/ and the Journal for Art Market Studies; https://www.fokum-jams.org/index.php/jams. 
In addition to these more structural properties of art market research, a more recent historiographical trend makes the inquiry into the use of digital methods particularly relevant. The boundaries of art markets as defined by researchers are becoming more fluid and contested, as can be observed on at least three levels. First, the history of art markets has since long been studied through economic, social, and cultural lenses. While some scholars still opt for one or the other, many researchers now try to integrate these perspectives through the topics of, for instance, intermediaries, market mediation, and valuation processes. The second trend plays out on a spatial level. The geographical reach of historical art market studies is increasingly more global, extending its focus beyond Europe and the United States to incorporate Latin America, Asia and Oceania. At the same time, scholars have developed increasing interest in themes such as cross-border trade and networks, global vs. national vs. local, and migration and mobility patterns. Finally, the historical narratives on the development of art markets are less homogeneous and linear, as more attention is being paid to different market segments and types of markets developing at different speeds, as well as to the relations between markets for paintings and markets for other cultural products, not only such as books, prints, photos and tapestries, but also musical, film, and theatrical productions.

The extension and opening up of disciplinary boundaries have added to our understanding of art markets as complex and multidimensional socio-cultural as well as economic phenomena. In theory, digitization, digital methods and linked data provide excellent opportunities for further advancing transdisciplinary, cross-border and comparative analyses. Open access to digital resources from art museums, archives, and libraries provides the opportunity, most explicitly perhaps in the form of linked data, to examine crossovers between research domains, periods, places, and to experiment with different explanatory models. However, as we observe in our own research practices and networks, it is difficult to systematically link or compare data across disciplines and borders, and to test theoretical models across different periods and places. For this issue, we therefore sought contributions that present a historical research question relevant to art market studies and we were particularly interested in contributions that reached out to other domains (be they time, place, or societal), and that emphasized combining and using multiple sources or data types (linked or not linked). There were no limitations as to place or time, as long as the papers were explicit on their research processes with regards to data, techniques and methods. This Special Issue showcases some of the aforementioned developments, reveals current practices and challenges, and points us to possible future research opportunities.

Thematically, the essays address many aspects of art markets and propose a wide array of operationalization strategies of art market research. In trying to understand career success within artistic communities and in the creative sector more broadly speaking, Braden \& Teekens propose a network approach to measure artistic status and reputation and use regression analysis to evaluate how these interact. Networks also feature in the McCabe's evaluation of Hans Rottenhammer's (ca. 1564-1625) international trajectory and the role that intermediaries played in the advancement of his career among patrons and the open markets principally in Venice, Rome, Antwerp, Augsburg and other cities. Also preoccupied with the role of institutions in artistic careers, Saint-Raymond quantitatively tests the resilience of the academic system and the French Salon and identifies the latter's lasting impact on artists' economic successes until the Great War, thus proposing that the establishment of the so-called dealer-critic system took root later that has been conceived to date. Fuchsgruber provides a reflection on current economic-sociological approaches to the study of art markets and emphasizes the complex relationship between markets and museums, illustrated by the case of maiolica forgeries in the photo archive of Verband von Museums-Beamten zur Abwehr von Fälschungen und unlauterem Geschäftsgebahren collectively maintained by museum officials in the early twentieth century. This archive, currently undergoing digitization, illuminates understudied aspects of museums' involvement in the market and the development of in-house expertise.

In order to explain the growth and development of local and regional art markets, Oberste-Hetbleck focuses on the role of art fairs in the internationalization of the markets for modern and contemporary art. In doing so, the mapping project ART|GALLERY GIS|COLOGNE recognizes and reflects on the 
role that digital platforms play in facilitating an integrated analysis of fairs and other art market phenomena. Also concerned with how art markets grow and develop, Nijboer, Brouwer \& Bok compare aspects of the painting industries in sixteenth- and seventeenth-century Antwerp and Amsterdam by analysing biographical data from ECARTICO, a database and linked data web resource on painters working in the Low Countries ca. 1475 to ca. 1725. In contrast to the long-held view that Amsterdam was the successor of Antwerp as the main artistic center in the Low Countries, the authors identify higher degrees of independence between the trajectories of the two local painting industries in terms of production figures and the producers' populations. Li also analyses ECARTICO data in tandem with production trends mined from the most comprehensive dataset of Netherlandish paintings of the RKD-Netherlands Institute for Art History. She presents novel visualizations of the painting production trends in the Northern Netherlands throughout the seventeenth century, which lead to explorations of incentives and constraints underlying the development of this industry in "irrational" ways that complicate the neoclassical economic approach to art market studies. Behavioral economics, outsider markets, information asymmetries, innovation and exuberance are also topics that surface in the coupled reflections by Van Miegroet, Alexander \& Leunissen and by Sidorova on the current state of contemporary art markets. The authors of both articles reflect on how online presence, digitization and technological advancements impact how art markets and research practices are conceived, and single out some challenges and opportunities for the application of analytical methods and tools to study the identified developments.

From these contributions, we can observe that the study of the commercial aspects of arts and culture is increasingly integrated by domain experts within disciplines such as art history. As a result, historical art markets can now be better understood as multilayered and complex socio-cultural structures that are not a given, but rather developing within specific social and societal contexts. The dialogue between historical and contemporary research further strengthens the critical reflection on art market sources and data and prompts discussions on what an art market is and how useful the concept is for historical research. While many of the topics covered here overlap and are central to the study of art markets, these contributions also demonstrate the specificity of place and time in art market inquiries and offer a reflection of established lines of research and availability of sources for each given topic. In other words, each period and place comes with its specific research interests, questions, and approaches, and the contents of this Special Issue in turn illuminates what is has not yet been systematically included, particularly in terms of time periods, geographic locations and artistic media.

The contributions in this Special Issue testify to the different ways in which digital collections and methods can be applied to historical research on art markets. While some articles are guided by more explicit questions and hypotheses, such as Braden \& Teekens and Saint-Raymond, scholars such as Fuchsgruber and Oberste-Hetbleck take specific datasets or sources to explore questions and topics and other authors, such as Li, McCabe, and Nijboer, Brouwer \& Bok can be situated in between explanatory/exploratory or question-driven/data-driven approaches. More speculative essays by Van Miegroet, Alexander \& Leunissen, as well as by Sidorova, offer timely reflections on current topics and research possibilities for the study of contemporary art markets. In fact, all the contributions provide hypotheses or starting points for further research. This type of research, then, provides insight into the iterative and sometimes more speculative character of digital research practices and therefore facilitates the (re-)use of datasets and models and the testing of hypotheses and assumptions. This also stems, at least partly, from the fact that, both in academia and cultural heritage institutions, specialized research-oriented datasets and online platforms are developed and tested in order to demonstrate potential and limitations of the data by means of specific use cases. Such big(gish) institutional or academic datasets help to elucidate the functioning of art markets by providing curated datasets (such as ECARTICO) as well as practices of data and tool criticism that work for different types of projects.

Indeed, in one way or another and in varying degrees of complexity, all the contributions rely on carefully curated corpora of source data compiled from a wide array of digital repositories or platforms, secondary printed material, and primary archival documents suited for specific inquiries. It stands out 
that for curating each of the corpuses, contributors overcame the challenges of constructing and linking datasets or enriching the available data with new complementary sources necessary to tackle their research questions. In all cases, the authors have been able to advance new digitization projects and take advantage of open access policies of digital resources from art museums, archives, and libraries. Fairs, galleries and auction sales catalogues, online museum collections and exhibition histories, digital provenance data and archival documents, prosopographical and image databases, art sales prices published online and art historical encyclopedias are some of the main sources brought together in these projects.

The articles thereby implicitly herald the need to formalize training in the development and the application of digital methods for the advancement of transdisciplinary, cross-border and comparative analyses by art market scholars and (art) historians. This type of research evidently requires interdisciplinary expertise, knowledge and skills that are still often self-taught or emerge from multidisciplinary research teams. In practice, it is still difficult and time-consuming to develop and identify good practices of data treatment, data modeling, and statistical analyses. When are the data good enough, how do we (re)present uncertainties and incompleteness and how do I publish the dataset, data models and statistics? How do I assess the functioning and usefulness of research tools and platforms? How do I present the research process in an article and where can I publish it? And, not unimportantly, who can review such interdisciplinary research? Translating the promise of digital methods into actual conceptual leaps in the field requires careful design of research questions, data models and methodologies. Even though historical researchers addressing these questions are being increasingly organised, these questions, many researchers, as well as authors in this special issue, are still developing their own definitions, measures and models.

In our view, digital research into art markets would benefit from a more systematic and open discussion on how to research art markets. This means engaging more explicitly with the conceptual aspects of art markets in order to define and operationalize variables and to interpret visual and statistical patterns. Here, current self-organising practices in the field of linked (open) data for heritage and historical research can perhaps serve as a source of inspiration. Linked data uses the Web to connect related data not previously linked that resides in heterogeneous and distributed datasets without superimposing a single model, but by using ontologies and vocabularies to define concepts and relationships and facilitate use and exchange. Such an approach as well as data principles (such as FAIR: Findable, Accessible, Interoperable, and Reusable ${ }^{3}$, and LOUD: Linked Open Usable Data ${ }^{4}$ ) might also be applied to research methods. This does not mean that communities of researchers have to arrive at unanimously shared definitions or data models, but rather that they have to ensure transparency about their methods in terms of definitions and data models concerning key concepts in research on art markets such as reputation, status, success, authenticity, incentives, constraints, relations, pricing, value, valuation, and value systems, intermediaries, and platforms. We hope and expect that the development of such conceptual and methodological frameworks will ensure the multiplicity of methods and ever-growing available data to more strongly impact existing research agendas and facilitate transdisciplinary, cross-border and comparative research. In the case of current art market developments, we expect that questions around digitization, online presence and methodological approaches to digital-born data and machine-generated and artificial intelligence (AI) tools will attract more scholarly attention in the future.

Funding: This research received no external funding.

Conflicts of Interest: The authors declare no conflicts of interest.

\footnotetext{
https://www.dtls.nl/fair-data/ (accessed 21 July 2019).

https://linked.art/loud/index.html (accessed 21 July 2019).
} 


\section{References}

Baca, Murtha, Anne Helmreich, and Nuria Rodríguez Ortega, eds. 2013. Digital Art History. Board-Approved Special Issue of Visual Resources, An International Journal of Documentation. 29: 1-2.

Baca, Murtha, Anne Helmreich, and Melissa Gill. 2019. Digital Art History. Visual Resources 35: 1-5. [CrossRef]

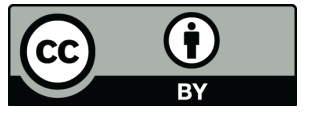

(C) 2019 by the authors. Licensee MDPI, Basel, Switzerland. This article is an open access article distributed under the terms and conditions of the Creative Commons Attribution (CC BY) license (http://creativecommons.org/licenses/by/4.0/). 